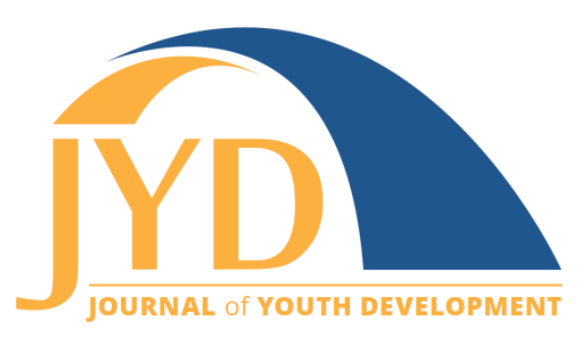

http://jyd.pitt.edu/ | Vol. 15 Issue 1 DOI 10.5195/jyd.2020.819 | ISSN 2325-4017 (online)

\title{
Creating a Rising Tide: Improving Social and Emotional Learning Across California
}

\section{Femi Vance}

American Institutes for Research

fvance@air.org

\section{Rebecca Goldberg}

S. D. Bechtel, Jr. Foundation

rgoldberg@sdbjrfoundation.org

\begin{abstract}
Given the recent emphasis on social and emotional development, many professionals who manage, develop, or influence expanded learning systems are beginning to ask, "How do we better prepare staff to promote social and emotional development?" California has adopted a statewide professional development strategy for publicly-funded expanded learning programs that is designed to raise awareness of the importance of social and emotional learning (SEL) among practitioners and build tools for the field to support implementation. The strategy-led by a partnership among a state agency, expanded learning intermediaries, and funders - combines leadership development, field-building initiatives, and program-level supports. It also complements the current expanded learning system. In this article, we describe the statewide strategy and discuss how it addresses workforce challenges, the core levers that California used to develop the strategy, and why and how the state-level leadership prioritized social and emotional learning. We conclude the article with lessons learned about collaboration, implementation, and assessing impact.
\end{abstract}

Key words: social and emotional learning, professional development, expanded learning

Social and emotional learning (SEL) is at the forefront of current education initiatives including expanded learning. SEL is the process by which youth learn the skills, values, attitudes, knowledge, and perspectives that enable them to thrive in their social and cultural contexts (Berg, Nolan, Osher, \& Mart, 2019). Managing emotions, cultivating social bonds, and responsible decision-making are a few examples of the competencies we hope young people

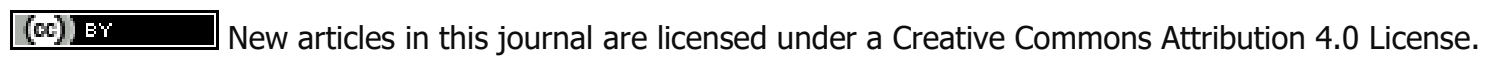
This journal is published by the University Library System, University of Pittsburgh and is cosponsored by the University of Pittsburgh Press. The Journal of Youth Development is the official peer-reviewed publication of the National Association of Extension 4-H Youth Development Professionals and the National AfterSchool Association. 


\section{Creating a Rising Tide}

will learn. In the report, From a Nation at Risk to a Nation at Hope, The National Commission on Social, Emotional, and Academic Development (2019) reminds us that SEL is a critical part of young people's development and that learning happens both in and out of school. Their conclusions highlight the role of expanded learning programs ${ }^{1}$ in preparing young people for civic engagement, careers, and healthy relationships.

Many of the conditions that support SEL, like a safe and supportive learning environment and strong relationships (Devaney \& Moroney, 2019; Farrington et al., 2012), are inherent in a positive youth development approach (Eccles \& Gootman, 2002; Hamilton, Hamilton, \& Pittman, 2004). Expanded learning professionals can build on the synergy between positive youth development and SEL if they have opportunities to strengthen their own social and emotional competencies and learn practices that promote these skills in youth.

In 2015, California adopted a statewide professional development strategy for their publiclyfunded expanded learning programs with the goal of preparing adults to support young people's social and emotional development. The philosophy underlying the strategy is that adults' SEL practices are mutable and can be leveraged to reach the desired goal. To enact this philosophy, California chose to leverage existing partnerships, systems, and resources to deliver SELfocused professional development. This article is an in-depth description of the statewide strategy, and its history from its inception in 2015 until the present (2019). Given the content, the article is most relevant to expanded learning professionals who design, manage, or seek to influence expanded learning systems.

\section{Prioritizing Social and Emotional Learning}

SEL emerged as a priority for California during an intensive, field-informed strategic planning process. With support from the S. D. Bechtel, Jr. Foundation and the David and Lucile Packard Foundation, the California Department of Education's Expanded Learning Division (the Division) led the planning process and designed it to explore new ways to support expanded learning programs.

\footnotetext{
${ }^{1}$ In this paper, "the term Expanded Learning refers to before and after school, summer, and intersession learning experiences that develop the academic, social, emotional, and physical needs and interests of students." See $A$ Vision for Expanded Learning in California: Strategic Plan 2014 - 2016.

https://www.cde.ca.gov/ls/ba/cp/documents/exldstrategicplan.pdf
} 
The Division's focus on SEL coincided with the state's participation in the Collaborating States Initiative $^{2}$ (CSI) led by the Collaborative for Academic, Social, and Emotional Learning (CASEL). CSI promotes a whole-child approach to learning to ensure that young people are prepared for the demands of adulthood. Participating states share best practices and create SEL plans that address their specific assets and opportunities. California's statewide professional development strategy advances several of the SEL guiding principles developed by the state's CSI planning team, whose members included staff from the Division (California Department of Education $[C D E], 2018)$. Notably, the strategy encourages adults and youth to practice social and emotional competencies, leverages the rich learning opportunities in expanded learning programs, enhances the expanded learning system, and provides ongoing professional learning.

The Division maintained the momentum around SEL by convening a statewide SEL planning committee comprised of experts and practitioners in the expanded learning field. The committee's task was to recommend specific steps that the Division could take to provide all youth access to high-quality SEL experiences. The final recommendations emphasize infusing SEL throughout California's extensive expanded learning system which supports over 4,500 programs that serve over 800,000 children and youth (Hay, 2018). ${ }^{3}$ The system offers programs targeted state funding, regional support, statewide quality standards, and a quality improvement system.

\section{Building a Statewide Team}

California's strategy for supporting SEL is the result of a collaboration among the Division, the S. D. Bechtel, Jr. Foundation, and five intermediaries: Partnership for Children and Youth (the Partnership), ASAPconnect, California Afterschool Network (the Network), California School-Age Consortium (CalSAC), and Temescal Associates. Each partner has a vested interest in California's expanded learning field and extensive experience supporting the workforce. Collectively, the intermediaries engage in technical assistance, professional development, advocacy, network- and coalition-building, leadership development, resource sharing, and

\footnotetext{
2 To learn more about CSI visit https://casel.org/collaborative-state-initiative/.

${ }^{3}$ The Network releases an annual State of the State of Expanded Learning Programs report for California. The report provides an update on the expanded learning system for publicly-funded programs. To learn more visit http://www.afterschoolnetwork.org/post/state-state-expanded-learning-california-2017-18
} 


\section{Creating a Rising Tide}

quality improvement (ASAPconnect, 2018; the Network, 2014; CalSAC, 2019a; the Partnership, n.d.; Temescal \& Associates, n.d.). The S. D. Bechtel, Jr. Foundation acknowledged the synergy between the Division's quality improvement efforts and SEL and funded the intermediaries to raise awareness about and support implementation of SEL in the field.

The collaboration among the five participating intermediaries is at the crux of California's model. While leading their individual initiatives supported by foundation funding, the intermediaries banded together to form one central body to help coordinate their work, develop cohesive messaging to the field about SEL, and maximize reach and impact. The resulting collaborative, Expanded Learning 360\%/365 (n.d.), charged itself with elevating how expanded learning programs contribute to SEL, providing SEL trainings and curricula, and encouraging expanded learning programs and schools to use and coordinate SEL practices in and out of school. They also committed to advancing policy that helps schools and programs deliver high-quality SEL supports. Harnessing their expertise, Expanded Learning 360\%/365 offered SEL-focused leadership development and field-building learning experiences to reach a cross section of the workforce. The collaborative also offered program-level supports to maximize the impact on the ground.

Early in the partnership, the collaborative defined the social and emotional competencies it wanted to impact. While there is a growing consensus in the field regarding the importance of SEL, there is little agreement about the language used to discuss social and emotional competencies. Hence, practitioners and scholars alike use multiple and imprecise terms to discuss these competencies (Berg et al., 2019; Jones, Bailey, Brush, Nelson, \& Barnes, 2016). In a brief, Student Success Comes Full Circle, Expanded Learning 360\%/365 (2015) identified and defined six foundational social and emotional competencies (see Figure 1). The brief helped establish consistent language around SEL in California. It also highlighted the features of expanded learning programs that support social and emotional competencies, effectively positioning expanded learning programs as a core support for youth and families. 
Figure 1. Expanded Learning $360^{\circ} / 365$ Foundational Areas

EXPANDED LEARNING $360^{\circ} / 365$

FOUNDATIONAL AREAS:

$-0-$

WE ARE

Self-awareness

Self-management

P

WE BELONG

Social awareness

Interpersonal skills

WE CAN

Self-efficacy

Growth mindset

\section{The Need for Statewide SEL Supports}

California's strategy to provide ongoing professional development addresses three workforce challenges. One is ensuring equitable access to professional development (Warner, Ham, \& Pearman Fenton, 2018). The strategy leverages statewide intermediaries as a way to ensure that programs across the state have access to professional development opportunities. And, since many programs are working on tight budgets, nearly all of the SEL learning opportunities are offered at no additional cost to participants. California's strategy also makes a concerted effort to unify the field around SEL, pushing consistent language and ensuring that staff at all levels understand the significance of SEL to their work. Starr and Gannet (2018) note that often professional development efforts are not cohesive; however, this statewide strategy is supported by the Division's efforts to bring SEL to the forefront of the expanded learning system. Finally, the California strategy fills a leadership development gap (Fowlkes \& McWhorter, 2018; Warner et al., 2018) by offering leadership development for middle managers (often called site coordinators) and creating settings where expanded learning professionals are engaging with other education leaders. 


\section{SEL-Focused Professional Development Opportunities}

Much like the broader expanded learning field, the professionals in California are a diverse group, which translates into a need for multiple approaches to professional development. Available evidence shows that the workforce has more females (65\%) than males and represents various racial/ethnic groups (48\% Latino, 31\% White, 9\% Black, 5\% Asian and 7\% other race/ethnicities; California Employment Development Department, 2012). Roughly 20\% of workers have a high school diploma or a GED and nearly a third (33\%) of the professionals have some college but have yet to earn a degree. In contrast, $25 \%$ have earned a bachelor's or graduate degree. Professional development strategies must accommodate the needs of such a varied group and fit the schedules of a workforce that is driven by part-time staff. Thus, Expanded Learning 360\%/365 employed multiple professional development modes including professional learning communities, technical assistance and support, conferences, SEL tools, training series, and certification (See Figure 2).

Figure 2. Expanded Learning: $360 \% / 365$ Modes of SEL Professional Development

\begin{tabular}{|c|c|c|}
\hline $\begin{array}{l}\text { - Strategic Plan }{ }^{a} \\
\text { - SEL Planning Teama } \\
\text { - System of Support and } \\
\text { Continuous Quality } \\
\text { Improvement (CQI) a }\end{array}$ & $\begin{array}{l}\text { - SEL Quality } \\
\text { Assessmentc } \\
\text { - System of Support } \\
\text { Technical Assistance } \\
\text { - CQI Training } \\
\text { - State of the State } \\
\text { - }\end{array}$ & $\begin{array}{l}\text { - System of Support } \\
\text { Technical Assistance } \\
\text { - School of Leadership } \\
\text { and Facilitation }\end{array}$ \\
\hline $\begin{array}{l}\text { The } \\
\text { Division }\end{array}$ & $\begin{array}{l}\text { The } \\
\text { Network }\end{array}$ & ASAP \\
\hline $\begin{array}{l}\text { - Training Certification } \\
\text { - SEL Training Series } \\
\text { - Leadership } \\
\text { - Development Institute } \\
\text { - Advocacy }\end{array}$ & $\begin{array}{l}\text { - Research and Reports } \\
\text { - District SEL Alignment } \\
\text { - Liaison to The Division } \\
\text { SEL Planning Team }\end{array}$ & $\begin{array}{l}\text { - How Kids Learn } \\
\text { Conference } \\
\text { - } 360 / 365 \text { Collaborative } \\
\text { Convener \& Content } \\
\text { Manager } \\
\text { - SEL Training and Tools }\end{array}$ \\
\hline CaISAC & The & Temescal \\
\hline
\end{tabular}

a Statewide infrastructure for professional development. ${ }^{b}$ Professional learning communities.

c Technical assistance and support. ${ }^{\mathrm{d}}$ Conferences. ${ }^{\mathrm{e}}$ Certification. ${ }^{\mathrm{f}} \mathrm{SEL}$ training and tools. 


\section{Creating a Rising Tide}

Given the varied professional development modes used by the different partners, it was not possible for the S. D. Bechtel, Jr. Foundation, to conduct an impact evaluation of the collaborative's efforts as a whole. Rather, the foundation worked with each intermediary to identify specific, measurable, achievable, relevant, and timely (SMART) objectives and encouraged the grantees to conduct formative evaluations to inform continuous improvement. The intermediaries used grant reports to reflect on progress towards their SMART objectives and to share how they might adapt their strategies based on new insights. The foundation staff advocate for this combination of formative evaluation, reflection, learning, and continuous improvement. Not coincidentally, this is the same cycle of learning and improvement that the Division encourages in its expanded learning sites. Table 1 shows that nearly 14,000 professionals participated in three different types of SEL-focused professional development opportunities from 2015 through 2019. This figure reflects the scale of potential impact.

Table 1. Participation in SEL-Focused Professional Development by Type (2015 2019)

\begin{tabular}{|l|c|}
\hline Professional development opportunity & Number of participants \\
\hline Leadership development & 158 \\
\hline Field building initiatives & 4,762 \\
\hline Supporting SEL practices in programs & 9,000 \\
\hline Total & $\mathbf{1 3 , 9 2 0}$ \\
\hline
\end{tabular}

\section{Leadership Development}

Expanded Learning 360\%/365 identified the need for more leadership development opportunities in California which echoes the larger leadership development gap in the field (Fowlkes \& McWhorter, 2018). The collaborative decided to use professional learning communities (PLC) as one way to address this gap. Traditionally used with teachers, PLCs have shown some success in changing both the knowledge and practice of expanded learning staff (Vance, Salvaterra, Atkins-Michelsen, \& Newhouse, 2016). The collaborative led a PLC for district teams that focused on aligning SEL practices across the school day and expanded learning programs. Research demonstrates that systematic and coordinated educational approaches among the family, community, and school are effective in promoting positive youth outcomes (Catalano, 


\section{Creating a Rising Tide}

Bergland, Ryan, Lonczak, \& Hawkins, 2002; Eccles \& Gootman, 2002; Oberle, Domitrovich, Meyers, \& Weissberg, 2016). This research laid the foundation for the PLC showing that greater alignment of SEL practices in schools and expanded learning programs will likely benefit youth.

Since 2015, 10 districts-including several CORE districts ${ }^{1}$ and their expanded learning partners-participated in the PLC on SEL alignment. Districts attended in teams ranging in size from five to 14 members with both district representatives (e.g., principals, teachers, training specialists) and expanded learning providers (e.g., executive directors, site coordinators, youth development specialists). Each district team focused on designing, implementing, or assessing their SEL alignment strategies. The teams attended in-person, quarterly PLC meetings and had access to 30 hours of in-depth support from a consultant. Through the PLC, districts also had access to a range of tools to guide their alignment strategies. For example, district teams developed an SEL alignment rubric to be used as a self-assessment in a quality improvement cycle (López, Miller, Houghton, Vance, \& Moroney, 2018). In an external, formative evaluation of the PLC researchers found that district teams had ongoing access to quality professional learning that guided them through a collaborative quality improvement cycle (López et al., 2018).

The Leadership Development Institute 360\%/365 (the Institute), is a fellowship for expanded learning supervisors structured like a PLC. The Institute "deepens the knowledge, skill and abilities of site coordinators and supervisory level staff to help staff and youth build a solid foundation of character" (CaISAC, 2019b, para. 1). Over the course of a year, a cohort of 14 to 16 fellows participate in more than 130 hours of professional learning including monthly meetings and assignments, leadership development plans, portfolios, presentations, a 3-day opening retreat, and a closing celebration. The Institute curriculum is filled with SEL content. For example, the fellows are introduced to individual and collective social and emotional skills, and they also engage in dialogue with prominent leaders about SEL in expanded learning programs. Interested professionals must apply to be a fellow, and since it was established in 2015, over 70 staff have graduated from the Institute. In interviews and summative evaluations of their learning experiences, fellows reported better understanding the significance of social and emotional competencies and how their own competencies impact their leadership styles and management approaches.

\footnotetext{
${ }^{1}$ CORE districts received a No Child Left Behind waiver in 2013 from the federal government that allowed the districts to overhaul the accountability systems to include academic and social and emotional measures. Since then the CORE districts have developed a nationally recognized school improvement and accountability system. To learn more about the CORE districts see https://coredistricts.org/.
} 


\section{Field-Building Initiatives}

The intent of field-building initiatives is to improve expanded learning professionals' fluency in SEL and to unify the expanded learning field around SEL. The Expanded Learning 360\%/365 field-building initiatives brought expanded learning professionals together to cross-pollinate ideas, practices, and resources while also promoting critical reflection on practice.

\section{Integrating SEL into Quality and System-Building}

The collaborative worked with the Division to promote SEL through the expanded learning system. Due to a state statute, California's publicly-funded expanded learning programs are required to engage in a data-driven quality improvement process. Additionally, the SEL planning team recommended developing a quality assessment tool that aligned with the quality standards, integrated high-quality SEL practices, and could be used in the quality improvement process. Currently, Expanded Learning $360^{\circ} / 365$ is developing the quality assessment tool, an accompanying guidebook on continuous quality improvement (CQI), and an online system of assessment. In tandem, the collaborative offers widespread training on the quality standards and the CQI process. In total, the collaborative has provided over 80 trainings on quality standards and CQI to roughly 2,400 expanded learning professionals.

\section{Certifying SEL Trainers}

Expanded Learning $360^{\circ} / 365$ increased the number of people who could provide SEL training in California by certifying trainers. To earn an SEL trainer certificate, practitioners applied to attend a 2-day training-of-trainers institute where they studied a set of new SEL training modules (see Supporting SEL Practices in Programs) and practiced using tried-and-true facilitation techniques. At the end of this training, participants are deemed "apprentice trainers" and must complete 16 hours of training, a self-assessment, and a formal training observation conducted by a certified trainer. Through the SEL certification, 79 trainers are now equipped to deliver SEL training in California.

\section{How Kids Learn Conference}

Since 2012, the annual How Kids Learn conference has built the capacity of expanded learning providers through interactive workshops and presentations (http://howkidslearn.org/). The 2014 conference theme, Character Building, Social and Emotional Learning, and Education Equity, explicitly focused on SEL. In other years, SEL content has been woven throughout workshops and presentations. An accompanying speaker series complements the conference and exposes expanded learning professionals to thought-leaders-both researchers and 


\section{Creating a Rising Tide}

practitioners-in the field. Speakers have covered the gamut of SEL-related topics: creating a culture of caring, developing a growth mindset, mindfulness, research on the effectiveness of expanded learning programs, and more. In total, the conference and speaker series reached 2,283 expanded learning professionals.

\section{Supporting SEL Practices in Programs}

Because Expanded Learning $360^{\circ} / 365$ recognized the need to intentionally focus on SEL practices to promote social and emotional competencies in youth (Moroney \& Devaney, 2017), it decided to offer program-level training that built the capacity of site teams to implement SEL best practices. The SEL training is delivered through nine 2-hour modules. The content of the modules focuses on how adults can promote the six focal social and emotional competencies. The content also covers how to align quality efforts with SEL practices and how to lead with SEL in mind. Program teams can choose to participate in the entire SEL series or select one or more trainings based on their professional development needs. Programs can also choose to host a site team PLC that uses the SEL modules as the curriculum. The PLC can be tailored to either frontline staff or to supervisory staff as prior research indicates that role-specific support can be beneficial (Vance, Atkins, Salvaterra, \& Newhouse, 2015).

The SEL modules are delivered by certified trainers who completed the aforementioned intensive certification process. Certified trainers provided over 850 hours of training to nearly 9,000 participants representing 155 agencies. To expand the reach of the trainings, Expanded Learning $360 \% / 365$ also offers the SEL modules on an e-learning platform.

\section{Core Levers for Implementation}

California possessed the levers needed to launch a statewide strategy for supporting the workforce to develop young people's social and emotional competencies. Arguably, the most important lever is the leadership of the Division which maintains the state's comprehensive expanded learning system. Expanded learning programs and staff in California benefit from quality standards to guide, motivate, and support CQI efforts. Clear messages from the Division emphasize the value of SEL in CQI and push practitioners to think critically about how to foster social and emotional competencies in youth.

The intermediaries work hand-in-hand with the Division. The relationships and expertise that each organization brought to Expanded Learning $360 \% / 365$ deepened the level of support provided to the field. In fact, the collaborative structured its work using a well-known 


\section{Creating a Rising Tide}

community agreement: "step up, step back." That is, the intermediary with the most expertise led the task while others played a supportive role (See Figure 2). Due to the intermediaries' long-standing working relationships, they entered Expanded Learning 360\%/365 with an understanding of one another's mission, capacity, and expertise.

Expanded Learning $360 \% / 365$ and the Division also had the backing of the S. D. Bechtel, Jr. Foundation, which prioritized SEL and character building in its grant-making. The foundation invested in the system-level strategic planning process led by the Division and awarded grants to each intermediary to lead the SEL work that they were primed to do. Foundation staff suggested a collaborative approach which the intermediaries quickly embraced and then formed Expanded Learning $360^{\circ} / 365$. Furthermore, the foundation staff highlighted the collaborative's SEL initiatives with funder audiences through speaking engagements and conferences.

Strong leadership from a state agency, engaged philanthropic partners interested in SEL, and statewide intermediaries emerged as core assets needed to build a statewide strategy for improving SEL practice in California. Each state possesses at least two of these assets, though finding similarly engaged philanthropic partners may be the most challenging to replicate. States interested in exploring how to provide statewide SEL supports may first leverage their statewide intermediary that exists in all states via the 50 State Afterschool Network (http://www.statewideafterschoolnetworks.net/) and the state agencies that have a vested interest in the success of publicly-funded expanded learning programs (e.g., $21^{\text {st }}$ Century Community Learning Centers). Together, these organizations can develop strategies for statewide SEL professional development that will fit the needs of their workforce in content and scope. They can also engage funders in these discussions, which may help garner resources for any new strategies that emerge.

\section{Lessons Learned}

Expanded Learning $360^{\circ} / 365$ is more of an umbrella term rather than a unified organization. And, as a result, the professional development opportunities offered by the collaborative are a combination of what each intermediary could provide. This approach was the best fit at the time and it came with tradeoffs.

\section{Lack of a Central Work-Plan}

Expanded Learning $360^{\circ} / 365$ (n.d.) was not initially part of the S. D. Bechtel, Jr. Foundation's California grant-making strategy. The Foundation knew that the participating intermediaries 


\section{Creating a Rising Tide}

worked closely with the Division. They also knew that the Division alone did not have the capacity to adequately support the promotion and implementation of SEL in a field of over 4,500 sites. To support the Division's work, the foundation chose to invest in a set of intermediaries that each had a unique reach into and influence on the field. If this collaborative structure had been part of the original strategy, however, these five organizations likely could have developed one statewide work plan with specific roles carved out for each organization. A central work plan might have led to more intentional collective impact on the field and measurable outcomes. Instead, the intermediaries came together to collaborate on messaging and promoted one another's work. As the initial grants are coming to a close in 2020, the five intermediaries are engaging in strategic planning to determine how they will sustain the SEL work and make it more cohesive.

\section{Need for a Stronger Focus}

The collaborative blanketed the field with a variety of resources. This approach is experimental by design mainly because the research on SEL practice was still maturing when the collaborative began. The five intermediaries tried multiple strategies based on their own strengths and experiences. They each understood the connection between SEL and quality youth development practice, but had not fully articulated how to integrate SEL into their own professional development offerings. Therefore, the intermediaries were building their own strengths and expertise in SEL as they were helping to build awareness in the field. A few of the strategies were not sustainable (i.e. focusing on positive behavior intervention and supports as a way to infuse SEL into programs). Thus, the partners iterated on their approaches based on formative evaluation results. In this way, the professional development strategy could be seen as a shotgun approach to testing different ideas to identify the most effective ways to support the workforce. Had the foundation taken a more focused approach, it might have invested in leading national SEL organizations to integrate SEL practices into the expanded learning field. However, it chose to build the capacity of the trusted expanded learning intermediaries in California to become leaders in SEL rather than ask more education-focused SEL organizations to adapt their tools and training for the expanded learning field.

\section{Desire to Plan Evaluation and Research Holistically}

It is difficult to articulate the impact of Expanded Learning $360^{\circ} / 365$ due to the lack of a central work-plan and the varied types of professional development opportunities. The only common data point is the number of practitioners that participated in each professional development opportunity (see Table 1). Otherwise, participants completed evaluations that were specific to 


\section{Creating a Rising Tide}

the individual learning opportunity. While there are some broad areas that are shared across these evaluations such as knowledge gained and perceived confidence, the specific content is too varied to make comparisons. Without being able to compare the learning opportunities, funders, the Division, and the intermediaries are also unable to identify the most effective professional development opportunities.

Given the scale of the statewide effort more research is needed to help inform the expanded learning field about how to bring SEL professional development to scale and to understand the benefits of doing so. Potential research questions include:

- How do programs align SEL training with CQI?

- How do expanded learning professionals apply their learning?

- What on-site support do expanded learning professionals need to apply their learning? Notably, the limitations that hinder holistic evaluation may also be germane to future research studies.

\section{Conclusion}

California's professional development strategy provides easily accessible SEL-focused professional development for leaders and staff in the expanded learning field. The strategy meets the needs of the California workforce by addressing a leadership development gap, creating a cohesive stance on and language about SEL, and promoting practices to foster social and emotional development. By offering opportunities across the state that demanded little fiscal investment from staff and programs California has also made professional development more accessible and equitable.

California's strategy brings together research and practical wisdom. It acknowledges that the success of young people hinges on our ability to equip the expanded learning workforce to nurture young people's social, emotional, and academic development. The field will need the intellect, experience, and resources of philanthropy, state agencies, and nonprofit intermediaries to forge ahead. Philanthropists can act as champions for SEL and can be catalysts, through grant-making and by promoting collaboration across organizational lines. Intermediaries must continue to invest in and deepen cooperative models that maximize organizational assets and relationships and minimize duplication of effort. They can also mobilize and engage expanded learning professionals to continue to offer high-quality learning experiences to youth. State agencies are in a position to convene all three sectors and initiate shifts in the und 
Journal of Youth Development | http://jyd.pitt.edu/ | Vol. 15 Issue 1 DOI 10.5195/jyd.2020.819

Creating a Rising Tide

erlying expanded learning infrastructure. As a whole, the expanded learning field must advance system-level change alongside on-the-ground pivots to create lasting impact on mindsets and practices that will promote social and emotional competencies in youth and adults

\section{References}

ASAPconnect. (2018). About Us. http://www.asapconnect.org/about

Berg, J., Nolan, E., Osher, D. \& Mart, A. (February, 2019). Social-emotional competencies in Context:

Using social-emotional learning frameworks to build educator's understanding. (Frameworks brief comparative series \#2). https://measuringsel.casel.org/wpcontent/uploads/2019/02/Frameworks-C.2-.pdf

California Afterschool Network. (2014). Our work. http://www.afterschoolnetwork.org/our-work

California Department of Education. (2018). California's social and emotional learning guiding principles. https://www.cde.ca.gov/eo/in/socialemotionallearning.asp

California Employment Development Department. (2012). 2012 After school program survey: Final report of results.

https://static1.squarespace.com/static/5981e865f14aa16941337125/t/5a7ca3d58165f5d59b3201 bd/1518117848397/AfterSchoolProgramSurvey FinalResults.pdf

California School-Age Consortium. (2019a). What we do. https://www.calsac.org/about-us

California School-Age Consortium. (2019b). Leadership development institute 360\%365: Building leaders with character. https://www.calsac.org/ldi-360365

Catalano, R. F., Berglund, M. L., Ryan, J. A. M., Lonczak, H. S., \& Hawkins, J. D. (2002). Positive youth development in the United States: Research findings on evaluations of positive youth development programs. Prevention \& Treatment, 5(1), 15a.

Devaney, E. \& Moroney, D. (2019). Focusing and framing SEL in OST: An introduction to the volume. In E. Devaney \& D. Moroney (Eds.) Social and emotional learning in out-of-school time (pp 3-24). Charlotte, NC: Information Age.

Eccles, J., \& Gootman, J. (Eds.). (2002). Community programs to promote youth development. Washington, DC: National Academy Press.

Expanded Learning 360\%/365. (2015) Student success comes full circle. http://el360365.weebly.com/uploads/1/1/0/6/110631901/pcy-fullcirclefinal.pdf

Expanded Learning 360\%/365. (n.d.) Mission \& purpose. https://el360-365.weebly.com/mission-purpose.html

Farrington, C. A., Roderick, M., Allensworth, E., Nagaoka, J., Keyes, T. S., Johnson, D. W., \& Beechum, N. O. (2012). Teaching adolescents to become learners: The role of noncognitive factors in shaping school performance: A critical literature review.

https://consortium.uchicago.edu/sites/default/files/2018-10/Noncognitive\%20Report 0.pdf 
Fowlkes, E., \& McWhorter, T. (2018). The leadership imperative. In H. Janc Malone \& T. Donahue (Eds.), The growing out-of-school time field: Past, present, and future, (pp. 133-146). Charlotte, NC: Information Age.

Hamilton, S. F., Hamilton, M. A., \& Pittman, K. (2004). Principles for youth development. The youth development handbook: Coming of age in American communities, 2, 3-22.

Hay, J. (2018). State of the state of expanded learning programs in California 2017-2018. California Afterschool Network. http://www.afterschoolnetwork.org/post/state-state-expanded-learningcalifornia-2017-18

Jones, S. M., Bailey, R., Brush, K., Nelson, B., \& Barnes, S. (2016). What is the same and what is different? Making sense of the "non-cognitive" domain. Helping Educators Translate Research into Practice. https://easel.gse.harvard.edu/files/gse-easel-lab/files/words matter paper.pdf

López, F., Miller, F., Houghton, S., Vance, F., Moroney, D. (2018). Expanded Learning 360/3650: Professional learning community evaluation. Washington, D.C.: American Institutes for Research.

Moroney, D. A., \& Devaney, E. (2017). Ready to implement? How the out-of-school time workforce can support character development through social and emotional learning: A review of the literature and future directions. Journal of Character Education, 13(1), p.67-87.

The National Commission on Social, Emotional, and Academic Development. (2019). From a nation at risk to a nation at hope: Recommendations from the national commission on social, emotional, and academic development. http://nationathope.org/report-from-the-nation/

Oberle, E., Domitrovich, C. E., Meyers, D. C., \& Weissberg, R. P. (2016). Establishing systemic social and emotional learning approaches in schools: A framework for schoolwide implementation. Cambridge Journal of Education, 46(3), 277-297.

Partnership for Children and Youth. (n.d.) About PCY. https://www.partnerforchildren.org/about-pcy-1 Starr, E., \& Gannett, E. (2018). The state of professional development: Past, present and future. In H. Janc Malone \& T. Donahue (Eds.), The growing out-of-school time field: Past, present, and future. (pp. 87-102). Charlotte, NC: Information Age.

Temescal Associates. (n.d.) About: What we do. https://temescalassociates.weebly.com/what-we-do.html

Vance, F., Atkins, J., \& Salvaterra, E., \& Newhouse, C. (2015). Professional learning communities in the expanded learning field. Oakland, CA: Public Profit. http://www.publicprofit.net/ProfessionalLearning-Communities-In-The-Expanded-Learning-Field

Vance, F., Salvaterra, E., Atkins-Michelsen, J., \& Newhouse, C. (2016). Professional learning communities: An alternative to the one-stop workshop. In K. M. Pozzoboni \& B. Kirshner (Eds.), The changing landscape of youth work, (pp. 147-165). Charlotte, NC: Information Age.

Warner, G., Ham, H., \& Pearman Fenton. (2018). Core competencies for the OST field. In H. Janc Malone \& T. Donahue (Eds.), The growing out-of-school time field: Past, present, and future. (pp. 103114). Charlotte, NC: Information Age. 